\title{
FORMAÇÃO DE PROFESSORES DA EDUCAÇÃO PROFISSIONAL: ANÁLISE DE PRODUÇÕES ACADÊMICAS
}

\author{
M. M. M. VIEIRA \\ Instituto Federal de Educação, Ciência e Tecnologia do Rio Grande do Sul \\ marilandi.vieira@sertao.ifrs.edu.br
}

Submetido 29/05/2015 - Aceito 22/02/2018

DOI: $10.15628 /$ holos.2018.3160

\section{RESUMO}

A educação profissional (EP) tem se configurado como importante campo de pesquisa. Por isso, este artigo trata do estado do conhecimento sobre a formação de professores para a EP e objetivou inventariar as produções acadêmicas acerca do tema apresentadas em eventos científicos no período de 2010 a 2017. Os procedimentos metodológicos adotados caracterizam-se pela abordagem qualitativa, do tipo pesquisa sobre pesquisas. No trabalho foram analisadas as produções acadêmicas apresentadas nos seguintes eventos: reuniões da ANPEd, ENDIPE, SENEPT e Colóquio Nacional A Produção do Conhecimento em Educação Profissional. A apreciação dos dados foi realizada por meio da análise de conteúdo, de Bardin
(2002). Constatou-se acentuado crescimento de pesquisas sobre o tema em relação aos estudos até 2009; as temáticas recorrentes foram: a) processo de constituição da docência/saberes docentes na educação profissional; b) políticas de formação dos seus professores; c) análise de programas ou cursos de formação de professores; d) relação entre formação e trabalho docente. Quanto aos procedimentos metodológicos, prevalecem pesquisas qualitativas, de campo e bibliográficas e, no primeiro caso, o lócus foram os Institutos Federais de Educação, Ciência e Tecnologia. $\mathrm{O}$ instrumento de produção dos dados mais utilizado foi a entrevista, realizada com professores que atuam na educação profissional.

PALAVRAS-CHAVE: Formação de professores, Educação profissional, Políticas educacionais.

\section{TEACHERS TRAINING OF PROFESSIONAL EDUCATION: ANALYSIS OF ACADEMIC PRODUCTIONS}

\begin{abstract}
The professional education (PE) has been configured as an important search field. Therefore, this article it's about the state of knowledge on training of teachers for $\mathrm{PE}$ and aims to inventory academic productions on the subject presented in scientific events in the 2010-2017 period. The methodological procedures adopted are characterized by qualitative approach, search about research type. In the work was analyzed the academic productions presented in the following events: meetings of ANPEd, ENDIPE, SENEPT and National Conference The Production of Knowledge in Professional Education. The evaluation of the data was performed through content analysis, by Bardin (2002). There was a marked increase in research on the subject in relation to studies up to 2009; the recurrent themes were: a) process of constitution of teaching / teacher knowledge in professional education; b) training policies of their
\end{abstract}

teachers; c) analysis of teacher training programs or courses; d) relationship between training and teacher work. About the methodological procedures, qualitative, field and bibliographic researches prevail, and in the first case, the locus was the Federal Institutes of Education, Science and Technology. The most widely used instrument of data production was the interview, carried out with teachers who work in professional education.

KEYWORDS: Teacher training, Professional education, Educational policies. 


\section{INTRODUÇÃO}

O tema formação de professores tem sido objeto de investigações realizadas sob as mais diversas perspectivas, mas revisando a literatura se constata que há inúmeros trabalhos abordando a formação docente para a educação básica (Gatti; Barretto, 2009; Gatti; Barretto; André, 2011) e a pedagogia universitária tem sido objeto de outros tantos estudos (Bolzan; Isaia, 2010, Veiga; Quixadá, 2010), porém, sobre a educação profissional (EP) o número de pesquisas têm sido restritas.

A partir de 2005 o Estado brasileiro passou a investir em políticas públicas para a ampliação da formação profissional articulada à escola regular. Pode-se citar como exemplos a criação, em 2005, do Programa de Integração da Educação Profissional ao Ensino Médio na Modalidade Educação de Jovens e Adultos (PROEJA); em 2008 a instituição dos Institutos Federais de Educação, Ciência e Tecnologia e, em 2011, o Programa Nacional de Acesso ao Ensino Técnico e Emprego (PRONATEC).

Assim, de acordo com o sitio da Rede Federal de Educação Profissional, Científica e Tecnológica (2016), entre 2003 e 2016, foram construídas 500 novas unidades e estão em funcionamento 644 campi, que cobrem todos os estados brasileiros, oferecendo cursos técnicos, superiores de tecnologia, licenciaturas, mestrados e doutorados. Essa ampliação da oferta de vagas e a diversidade dos cursos tem exigido a contratação de novos docentes, o que reforça a importância da formação dos professores que ocupam esses novos cargos.

Entretanto, o que se constata, em termos de políticas públicas para a formação dos professores da EP, é que esse ainda é um desafio, pois persiste a heterogeneidade da formação profissional, já que ainda não há a exigência legal de conclusão de curso de licenciatura para atuação nessa modalidade de ensino.

Assim, o artigo inventaria as produções acadêmicas sobre formação de professores para a EP, apresentadas em eventos na área da educação no período de 2010 a 2017, fundamentado pela seguinte questão: Como está sendo abordada a formação de professores para a educação profissional nas pesquisas apresentadas nos eventos educacionais realizados no Brasil?

\section{REVISÃO BIBLIOGRÁFICA}

Os estudos sobre a formação de professores da EP publicados até 2008, em sua maioria, tiveram como foco a revisão histórica da constituição da área e as legislações a ela pertinentes, tais como os de Peterossi (1994) e Machado (2008). Esta última aponta a necessidade de criação de curso de licenciatura para a formação de professores e os desafios enfrentados pelos profissionais que atuam na área. Ela diz:

Os professores de educação profissional enfrentam novos desafios relacionados às mudanças organizacionais que afetam as relações profissionais, aos efeitos das inovações tecnológicas sobre as atividades de trabalho e culturas profissionais, ao novo papel que os sistemas simbólicos desempenham na estruturação do mundo do trabalho, ao aumento das exigências de qualidade na produção e nos serviços, à exigência de maior atenção à justiça social, às questões éticas e de sustentabilidade ambiental. São novas demandas à construção e reconstrução dos saberes e conhecimentos fundamentais à análise, reflexão e intervenções críticas e criativas na atividade de trabalho (Machado, 2008, p. 15). 
Pena (2011) inventariou as produções acadêmicas sobre a formação de professores para a EP produzidas no período de 2000 a 2009 que constam no Banco de Teses da Capes, nos trabalhos apresentados no GT 8 - Formação de professores, da ANPEd, e na Revista Brasileira de Educação, nos Cadernos de Pesquisa e Educação e Sociedade e concluiu pela ausência de trabalhos nessa área. Pena (2011) localizou duas dissertações no Banco de Teses da Capes e três trabalhos apresentados na ANPEd. Já nos periódicos analisados a autora confirmou a escassez de pesquisas sobre o tema, o que indicava uma demanda para novas investigações.

Essa é a mesma conclusão que aponta o estudo de Baptaglin (2013) que investigou as produções acadêmicas e científicas sobre o tema presentes nos levantamentos realizados pela Rede Sulbrasileira de Investigadores da Educação Superior (RIES), os periódicos da área (Revista Brasileira de Educação Profissional e Tecnológica e Revista Brasileira de Educação - ANPEd), nos materiais constantes no sitio da Secretaria de Educação Profissional e Tecnológica - SETEC e no Portal de dissertações e teses da CAPES no período compreendido entre 1984 e 2010.

Assim, os estudos mencionados apontam a escassez de pesquisas sobre a formação de professores para a EP e essa situação, segundo Gariglio e Burnier (2012), é decorrente de dois fatores: a) o fato de que o ensino técnico ter sido criado para atender aos interesses e às necessidades produtivas do mundo empresarial e sua desarticulação em relação à escola regular fez com que as instituições de formação profissional organizassem os cursos com uma visão empresarial, incorporando em sua estrutura e organização, procedimentos eminentemente utilitários; e b) o desprestígio dessa modalidade de ensino em relação à educação propedêutica, que reflete a relação de inferioridade com que o trabalho manual é percebido diante do intelectual. Soma-se a isso o fato dos cursos serem destinados aos excluídos da sociedade: órfãos, abandonados e "desvalidos da sorte".

Assim, neste trabalho foram investigadas as produções acadêmicas que trataram da formação de professores para a educação profissional.

\section{METODOLOGIA}

Este estudo apresenta o estado de conhecimento sobre formação de professores para a EP e a constituição desse tipo de pesquisa, segundo Haddad (2002, p. 9)

[...] permite, num recorte temporal definido, sistematizar um determinado campo do conhecimento, reconhecer os principais resultados da investigação, identificar temáticas e abordagens dominantes e emergentes, bem como lacunas e campos inexplorados abertos a pesquisas futuras.

Os procedimentos metodológicos utilizados seguem a abordagem qualitativa, do tipo pesquisa sobre pesquisas porque partiu da análise documental dos trabalhos apresentados em eventos sobre o tema formação de professores da EP no período de 2010 a 2017.

Assim, na primeira etapa de elaboração do trabalho foram acessados os sítios dos seguintes eventos: reuniões da Associação Nacional de Pós-Graduação e Pesquisa em Educação ANPEd - (2010 a 2017), Encontro Nacional de Didática e Prática de Ensino - ENDIPE (2010, 2012, 2014, 2016), Seminário Nacional de Educação Profissional e Tecnológica - SENEPT (2010, 2012, 
$2017^{1}$ ) e Colóquio Nacional A Produção do Conhecimento em Educação Profissional (2013, 2015, $2017^{2}$ ). A opção pelas reuniões da ANPEd e o ENDIPE ocorreu devido à abrangência dos eventos, tanto em relação às temáticas, quanto a diversificação dos participantes. Já o SENEPT e o Colóquio, foram escolhidos porque são promovidos por instituições que oferecem programas de mestrado em educação profissional e, portanto, dão visibilidade à temática formação de professores para essa modalidade de ensino.

Nos Anais dos eventos foram mapeados os trabalhos que tratavam do tema, utilizando-se como procedimento a leitura do título, resumo e palavras-chave (educação profissional formação de professores - políticas de formação de professores) e foram localizados inicialmente cinquenta trabalhos.

Na segunda etapa procedeu-se a leitura e análise dos trabalhos selecionados, porém foi realizado um recorte do tema, priorizando os referentes a professores das disciplinas técnicas, excluindo os estudos que trataram da formação de licenciados, mesmo que o lócus da pesquisa tenha sido os IFES, além dos que trataram exclusivamente de experiências de formação continuada, dada a sua curta duração e caráter pontual e descontínuo. O corpus desse trabalho, portanto, foi constituído por trinta e nove trabalhos, conforme quadro 01:

Quadro 1: Produção acadêmica sobre formação de professores para a EP - 2010 a $2017^{3}$

\begin{tabular}{|c|c|c|c|}
\hline № & TíTULO & AUTOR/ES & EVENTO/ANO \\
\hline 01 & O trabalho docente na educação profissional técnica. & Menezes, Graziela N. D. & ANPED 2015 \\
\hline 02 & A formação de professores para a educação profissional. & Oliveira, Maria R. N. & ENDIPE 2010 \\
\hline 03 & $\begin{array}{l}\text { Formação de professores para a educação profissional e } \\
\text { tecnológica e a necessária atitude docente integradora. }\end{array}$ & Araújo, Ronaldo M. L. & ENDIPE 2010 \\
\hline 04 & $\begin{array}{l}\text { Formação de professores para a educação profissional e } \\
\text { tecnológica. }\end{array}$ & Kuenzer, Acácia Z. & ENDIPE 2010 \\
\hline 05 & $\begin{array}{l}\text { Formação pedagógica do professor da educação profissional e } \\
\text { tecnológica. }\end{array}$ & $\begin{array}{l}\text { Santos, Luciana D.N.; } \\
\text { Fighera, Adriana C.M.; } \\
\text { Juchem, Luiza de S. }\end{array}$ & ENDIPE 2010 \\
\hline 06 & $\begin{array}{l}\text { A identidade docente na educação profissional: como se forma o } \\
\text { professor. }\end{array}$ & Paiva, Cantaluce M. F. & ENDIPE 2012 \\
\hline 07 & A docência da educação profissional e os saberes docentes. & $\begin{array}{l}\text { Vieira, Marilandi M.M; } \\
\text { Vieira, Josimar de A. }\end{array}$ & ENDIPE 2014 \\
\hline 08 & $\begin{array}{l}\text { As políticas de formação de professores da educação profissional } \\
\text { no Brasil: concepções e desafios. }\end{array}$ & Silva, Filomena R. da & ENDIPE 2014 \\
\hline 09 & $\begin{array}{l}\text { A viabilidade da educação a distância para a formação de } \\
\text { professores para a educação profissional. }\end{array}$ & $\begin{array}{l}\text { Passos, Sara R. M S. } \\
\text { Barbosa, Jane R. Alves }\end{array}$ & ENDIPE 2014 \\
\hline 10 & $\begin{array}{l}\text { Narrativas de professores: revelando a profissionalidade docente e } \\
\text { sua construção na educação profissional e tecnológica. }\end{array}$ & Orsano, Ana C. F. & ENDIPE 2016 \\
\hline 11 & $\begin{array}{l}\text { Trajetória da formação de professores para a educação } \\
\text { profissional. }\end{array}$ & Barbosa, Jane R. Alves & ENDIPE 2016 \\
\hline
\end{tabular}

\footnotetext{
${ }^{1}$ Não foram incluídos possíveis trabalhos apresentados no IV SENEPT (2014) e V SENEPT (2017) porque os Anais dos eventos não foram localizados.

${ }^{2}$ Os trabalhos apresentados no I Colóquio (2011) não constam no sitio do evento e, analisando os trabalhos apresentados no II Colóquio (2013) - Eixo Temático III - Formação de professores para a educação profissional constatou-se que tratam de vários aspectos relativos à docência, mas nenhum se referiu a esse tema.

${ }^{3}$ Optou-se por apresentar os dados dos trabalhos na tabela para facilitar a leitura. Por considerar que as principais informações estão nela contidas, não os inserimos nas referências. Os mesmos podem ser localizados nos Anais dos eventos disponíveis na Internet.
} 


\begin{tabular}{|c|c|c|c|}
\hline 12 & $\begin{array}{l}\text { Os saberes docentes na educação profissional: impactos e novos } \\
\text { desafios. }\end{array}$ & Passos, Sara R. M. S. & ENDIPE 2016 \\
\hline 13 & Os saberes docentes dos professores da rede E-TEC BRASIL. & Pasqualli, Roberta & ENDIPE 2016 \\
\hline 14 & $\begin{array}{l}\text { Conhecimento pedagógico do conteúdo na docência da educação } \\
\text { profissional. }\end{array}$ & $\begin{array}{l}\text { Vieira, Marilandi M. M; } \\
\text { Vieira, Josimar de A. }\end{array}$ & ENDIPE 2016 \\
\hline 15 & $\begin{array}{l}\text { A produção acadêmica sobre o trabalho e formação docente para } \\
\text { a educação profissional. }\end{array}$ & Cruz, Shirleide P. S. & ENDIPE 2016 \\
\hline 16 & $\begin{array}{l}\text { Saberes docentes na educação profissional: um estudo de caso no } \\
\text { contexto capixaba. }\end{array}$ & $\begin{array}{l}\text { Silva; Maria da P. T.; } \\
\text { Santos, Ana C. S. }\end{array}$ & ENDIPE 2016 \\
\hline 17 & $\begin{array}{l}\text { Formação pedagógica para a docência na educação profissional e } \\
\text { tecnológica: desafios e possibilidades. }\end{array}$ & $\begin{array}{l}\text { Liberalesso, Rita Cacia } \\
\text { B. }\end{array}$ & SENEPT 2010 \\
\hline 18 & $\begin{array}{l}\text { Formação docente e aprendizagem da docência: um olhar sobre a } \\
\text { educação profissional. }\end{array}$ & Pena, Geralda A. C. & SENEPT 2010 \\
\hline 19 & $\begin{array}{l}\text { Os desafios de ser docente na educação profissional e tecnológica } \\
\text { no Brasil: vida e formação se entrecruzam na constituição do } \\
\text { habitus professoral. }\end{array}$ & $\begin{array}{l}\text { Lima, Vivian C.; Baldino, } \\
\text { José M.; Fernandes, } \\
\text { Juliana C. }\end{array}$ & SENEPT 2012 \\
\hline 20 & $\begin{array}{l}\text { Os professores da educação profissional e tecnológica: sua } \\
\text { formação, seus saberes e práticas profissionais. }\end{array}$ & \begin{tabular}{lrr} 
Gariglio, & \multicolumn{1}{c}{ José } & A.; \\
Burnier, & Suzana & L; \\
Oliveira, & Maria & R.S.N; \\
Silva, & Maria & A.; \\
Valentim, Silvani S. & \\
\end{tabular} & SENEPT 2012 \\
\hline 21 & $\begin{array}{l}\text { Políticas de formação de professores para a educação profissional } \\
\text { e tecnológica no Brasil: desafios históricos e perspectivas } \\
\text { contemporâneas. }\end{array}$ & Costa, Maria Adélia & SENEPT 2012 \\
\hline 22 & Por uma nova formação docente na educação profissional. & $\begin{array}{l}\text { Wollinger, Paulo R.; } \\
\text { Allain, Olivier; Gruber, } \\
\text { Crislaine. }\end{array}$ & SENEPT 2017 \\
\hline 23 & $\begin{array}{l}\text { A formação de professores para o ensino profissional no Brasil: a } \\
\text { construção de um caminho. }\end{array}$ & $\begin{array}{l}\text { Andrade; Maria do C. F; } \\
\text { Souza, Ana Claudia R. }\end{array}$ & $\begin{array}{c}\text { Colóquio } \\
2015\end{array}$ \\
\hline 24 & $\begin{array}{l}\text { Formação de professores para a educação profissional e } \\
\text { tecnológica a distância da rede federal de educação brasileira: } \\
\text { análise das produções acadêmicas. }\end{array}$ & $\begin{array}{l}\text { Pasqualli, Roberta; } \\
\text { Vieira, Marilandi M. M; } \\
\text { Vieira, Josimar de A. }\end{array}$ & $\begin{array}{l}\text { Colóquio } \\
2015\end{array}$ \\
\hline 25 & $\begin{array}{l}\text { Percurso histórico da formação de professores para educação } \\
\text { profissional no Brasil (séculos XX-XXI). }\end{array}$ & $\begin{array}{l}\text { Rodrigues; laponira da } \\
\text { S; Souza, Francisco C. S }\end{array}$ & $\begin{array}{c}\text { Colóquio } \\
2015\end{array}$ \\
\hline 26 & $\begin{array}{l}\text { Produção do conhecimento sobre políticas de formação docente } \\
\text { para a educação profissional: } 2010 \text { a } 2014 \text {. }\end{array}$ & $\begin{array}{l}\text { Medeiros, Dayvyd L. M.; } \\
\text { Tavares, Andrezza M. } \\
\text { B.N. }\end{array}$ & $\begin{array}{l}\text { Colóquio } \\
2015\end{array}$ \\
\hline 27 & $\begin{array}{l}\text { Formação docente para a educação profissional: relato de uma } \\
\text { experiência de pesquisa. }\end{array}$ & $\begin{array}{l}\text { Henrique, Ana Lúcia S.; } \\
\text { Cavalcante, Ilane F. }\end{array}$ & $\begin{array}{c}\text { Colóquio } \\
2015\end{array}$ \\
\hline 28 & $\begin{array}{l}\text { A formação docente para a EPT: um estudo sobre a percepção de } \\
\text { formação integral e integrada dos professores do curso de } \\
\text { Informática do IFRN. }\end{array}$ & $\begin{array}{l}\text { Souza, Marcela R. G. de; } \\
\text { Silva, Maria de L. T.; } \\
\text { Silva, Maria do S. }\end{array}$ & $\begin{array}{l}\text { Colóquio } \\
2015\end{array}$ \\
\hline 29 & $\begin{array}{l}\text { Professor bacharel na educação profissional: saberes necessários à } \\
\text { atuação docente. }\end{array}$ & $\begin{array}{l}\text { Paiva, Samara Y. de; } \\
\text { Henrique, Ana Lúcia S. }\end{array}$ & $\begin{array}{c}\text { Colóquio } \\
2015\end{array}$ \\
\hline 30 & Formação docente e narrativas de engenheiros professores. & $\begin{array}{l}\text { Silva; Silvia H. S. C; } \\
\text { Souza, Francisco C. S. }\end{array}$ & $\begin{array}{c}\text { Colóquio } \\
2015 \\
\end{array}$ \\
\hline 31 & $\begin{array}{l}\text { Formação de professores da educação profissional nos Programas } \\
\text { Especiais de Formação Pedagógica. }\end{array}$ & $\begin{array}{l}\text { Vieira, Marilandi M. M; } \\
\text { Vieira, Josimar de A.; } \\
\text { Pasqualli, Roberta. }\end{array}$ & $\begin{array}{l}\text { Colóquio } \\
2015\end{array}$ \\
\hline 32 & $\begin{array}{l}\text { Formação de professores para a educação profissional e } \\
\text { tecnológica: o olhar da legislação }(1917-2017) \text {. }\end{array}$ & $\begin{array}{l}\text { Meneses Filho, Antônio; } \\
\text { Costa, Maria A. }\end{array}$ & $\begin{array}{c}\text { Colóquio } \\
2017\end{array}$ \\
\hline 33 & $\begin{array}{l}\text { A formação de professores para a educação profissional e o } \\
\text { notório saber: uma ponte para o passado. }\end{array}$ & $\begin{array}{l}\text { Costa; Maria A; } \\
\text { Coutinho, Eduardo H.L. }\end{array}$ & $\begin{array}{c}\text { Colóquio } \\
2017\end{array}$ \\
\hline 34 & $\begin{array}{l}\text { Formação docente para o uso das TIC no contexto da educação } \\
\text { profissional: por um diálogo com a formação humana integral. }\end{array}$ & $\begin{array}{l}\text { Mororó; Dediane C. S. } \\
\text { Nascimento, José M. }\end{array}$ & $\begin{array}{c}\text { Colóquio } \\
2017\end{array}$ \\
\hline
\end{tabular}




\begin{tabular}{|c|l|lc|c|}
\hline 35 & $\begin{array}{l}\text { Formação de docente não licenciado: desafio da educação } \\
\text { profissional. }\end{array}$ & $\begin{array}{l}\text { Nascimento Jr; Albertino } \\
\text { F; Leiro, Augusto C. R. }\end{array}$ & $\begin{array}{c}\text { Colóquio } \\
2017\end{array}$ \\
\hline 36 & $\begin{array}{l}\text { Docentes não licenciados que atuam na educação profissional: } \\
\text { relação entre formação, saberes e práticas. }\end{array}$ & $\begin{array}{l}\text { Silva; Alyne C. da; } \\
\text { Henrique, Ana Lúcia S. }\end{array}$ & $\begin{array}{c}\text { Colóquio } \\
2017\end{array}$ \\
\hline 37 & $\begin{array}{l}\text { Entre o notório saber e o domínio teórico: a formação docente } \\
\text { para a educação profissional entre as décadas de 1940 e 1950. }\end{array}$ & $\begin{array}{l}\text { Machado, Maria L. B. } \\
\text { Colóquio } \\
2017\end{array}$ \\
\hline 38 & $\begin{array}{l}\text { Reforma do ensino médio e formação de professores para a } \\
\text { educação profissional: nova lei - velhos interesses. }\end{array}$ & $\begin{array}{l}\text { Costa, Maria C. F. S; } \\
\text { Silva; Margareth N. da; } \\
\text { Lemos, Luiz H. G. }\end{array}$ & $\begin{array}{c}\text { Colóquio } \\
2017\end{array}$ \\
\hline 39 & $\begin{array}{l}\text { Conhecimentos docentes necessários à formação e atuação na } \\
\text { educação profissional: reflexões de docentes do Instituto Federal } \\
\text { de Brasília. }\end{array}$ & $\begin{array}{l}\text { Brito, Claudirene S.; } \\
\text { Cruz, Shirleide P. S. }\end{array}$ & $\begin{array}{c}\text { Colóquio } \\
2017\end{array}$ \\
\hline
\end{tabular}

$\mathrm{Na}$ terceira etapa, foi realizada a leitura flutuante (Bardin, 2002) do conteúdo das produções e os elementos transcritos para uma planilha do Microsoft Excel visando facilitar a categorização, realizada por meio da análise de conteúdo, que, segundo Bardin $(2002$, p. 46) é

Um conjunto de técnicas de análise das comunicações que, através de procedimentos sistemáticos e objetivos de descrição do conteúdo das mensagens, visa obter indicadores (quantitativos ou não) que permitam a inferência de conhecimentos relativos às condições de produção e de recepção (variáveis inferidas) destas mensagens.

Assim, procurou-se verificar a presença de ideias que se repetiam por meio de vocábulos com o mesmo sentido. Em seguida, procedeu-se a exploração do material, agrupando os relatos que continham ideias semelhantes, procedendo-se à codificação de unidades de registro em categorias de análise. Posteriormente, fez-se o tratamento dos resultados, inferência e interpretação, ou seja, procurou-se analisar o conteúdo expresso, que constituíram duas categorias centrais: temáticas investigadas/conclusões e caracterização metodológica (tipo, abordagem do problema, técnicas e instrumento de produção dos dados, lócus e sujeitos pesquisados, etc) conforme apresentado a seguir.

\section{RESULTADOS E DISCUSSÕES}

\subsection{Temáticas abordadas}

A leitura dos resumos e dos trabalhos permitiu organizar as temáticas investigadas em quatro categorias, conforme consta no Quadro 2.

Quadro 2: Temáticas dos trabalhos sobre formação de professores para a EP - 2010 a 2017

\begin{tabular}{|l|l|c|c|}
\hline \multicolumn{1}{|c|}{ TEMÁTICAS } & \multicolumn{1}{|c|}{ TRABALHOS/AUTOR } & No & $\%$ \\
\hline $\begin{array}{l}1 \text { Processo de constituição da } \\
\text { docência/saberes docentes na EP }\end{array}$ & $\begin{array}{l}\text { Menezes (2015) - Paiva (2012) - Vieira; Vieira (2014) - } \\
\text { Orsano (2016) - Passos (2016) - Pasqualli (2016) - Vieira; } \\
\text { Vieira (2016) - Silva; Santos (2016) - Pena (2010) - Lima; }\end{array}$ & 35,8 \\
& $\begin{array}{l}\text { Baldino; Fernandes (2015) - Gariglio et al (2012) - Paiva; } \\
\text { Henrique (2015) - Silva; Henrique (2017) - Brito; Cruz (2017) }\end{array}$ & \\
\hline $\begin{array}{l}\text { 2 Análise das políticas de formação } \\
\text { de professores para a EP }\end{array}$ & $\begin{array}{l}\text { Oliveira (2010) - Silva (2014) - Barbosa; Passos (2014) - } \\
\text { Barbosa (2016) - Costa (2012) - Andrade; Souza (2015) - }\end{array}$ & 30,8 \\
& $\begin{array}{l}\text { Rodrigues; Souza (2015) - Medeiros; Tavares (2015) - } \\
\text { Meneses Filho; Costa (2017) - Costa; Coutinho (2017) - }\end{array}$ & \\
\hline 3 Análise de programas ou cursos & Sachado (2017) - Costa; Silva; Lemos (2017). & 12,8 \\
\hline
\end{tabular}




\begin{tabular}{|l|l|c|c|}
\hline $\begin{array}{l}\text { de formação de professores para a } \\
\text { EP. }\end{array}$ & $\begin{array}{l}\text { Wollinger; Allain; Gruber (2017) - Vieira; Vieira; Pasqualli } \\
\text { (2015) - Nascimento Júnior; Leiro (2017). }\end{array}$ & \\
\hline 4 Formação e trabalho docente & Araújo (2010) - Kuenzer (2010) - Cruz (2016) - Pasqualli; & 8 & 20,6 \\
& Vieira; Vieira (2015) - Henrique; Cavalcante (2015) - Souza; & \\
& $\begin{array}{l}\text { Silva; Silva (2015) - Silva; Souza (2015) - Mororó; } \\
\text { Nascimento (2017). }\end{array}$ & \\
\hline
\end{tabular}

\subsubsection{Processo de constituição da docência/saberes docentes na EP}

Nesta categoria foram incluídos catorze trabalhos, que tem em comum a análise sobre como os professores da EP se constituíram docentes e desenvolveram os saberes requeridos pela profissão, já que, em sua maioria, são profissionais sem formação pedagógica. A seguir apresentamos uma breve descrição sobre cada trabalho.

Menezes (2015) analisa como as experiências de vida, formação e profissão tecem a constituição da docência e como os sentidos de trabalho e de técnica atravessam a profissão dos professores na EP. Segundo Menezes, os dados indicam que a ausência de projeto pedagógico no lócus da pesquisa não impulsiona novos formatos para a docência e prevalece, entre os docentes, a concepção "sobre o fazer técnico como mero aparato instrumental de apropriação da natureza e do próprio trabalho humano, sendo regido por valores de competitividade e de exclusão daqueles que não se ajustam às leis do mercado" (Menezes, 2015, p. 14).

O trabalho de Paiva (2012) buscou compreender como os professores do ensino técnico constituem a identidade docente articulando conhecimentos adquiridos na formação inicial e os saberes construídos na prática docente. Paiva concluiu que a constituição da identidade docente está imbricada nos processos de socialização primária e secundária vivenciados nas experiências na família, escola, referências pessoais e sociais, atividades pré-profissionais, e, de modo significativo e determinante, no exercício da docência, no qual os professores expressam identidade "afirmadora como professor", realçada na certeza e consolidação da "atuação profissional" na carreira do magistério.

O objetivo do trabalho de Vieira e Vieira (2014) foi identificar os saberes mobilizados pelos professores da EP na gestão da aula que mais contribuem para a aprendizagem, segundo os estudantes. O estudo apontou como relevantes o domínio de conhecimentos da área de formação, habilidade de relacionar os conteúdos com as exigências da profissão e da forma de organização e gestão da aula, como a seleção de estratégias de ensino, comunicação e interação com os estudantes e o estabelecimento de clima adequado ao ensino e a avaliação da aula.

Orsano (2016) tratou sobre o desenvolvimento da profissionalidade docente construída no exercício profissional a partir das narrativas de professores bacharéis e concluiu que a educação profissional e tecnológica mantém na identidade profissional docente a construção de posturas tecnicistas, com habilidades para o uso de novas tecnologias, mas com desafios a serem vencidos acerca da necessária formação docente.

Passos (2016) também abordou os saberes da docência para a EP e concluiu que ela é um ofício de saberes em que o professor precisa saber-fazer e saber ser professor, o que desconstrói o senso comum de que o professor da área técnica só precisa saber-fazer. Nesse sentido, Passos 
(2016) defende a urgência de criação de formas de acolhida aos docentes da EP nas instituições escolares, promovendo espaços formativos para os professores dessa modalidade de ensino.

O tema de Pasqualli (2016) foi os saberes docentes mobilizados pelos professores da EP na modalidade de educação a distância e como eles orientam as ações e tencionam o trabalho docente. Aponta a escassez de estudos sobre a temática e destaca como fundamentais à atividade docente na EAD os seguintes saberes: dos contextos dos estudantes, da linguagem, da utilização dos aparatos tecnológicos, da generosidade, do mundo do trabalho e da formação humana não utilitarista.

O conhecimento pedagógico do conteúdo (Shulman, 2005), foi o tema de Vieira e Vieira (2016) que analisaram como ele se configura na formação e na docência da EP. Os autores concluem que a formação para a docência contribui para o domínio de técnicas de ensino, mas também para que os docentes percebam a amplitude e as exigências do processo ensinoaprendizagem e construam estratégias de comunicação e interação com os alunos, de investigação e reconhecimento de seus saberes, de projetar-se neles e tentar compreendê-los, além de experimentar diferentes formas de ajudá-los a apropriarem-se de conteúdos escolares construindo conhecimentos, conjunto de habilidades que constituem o conhecimento pedagógico do conteúdo.

Silva e Santos (2016) identificaram os aspectos da constituição docente na EP e os saberes que influenciam nesse processo, segundo a concepção dos professores, indicando os aspectos singulares da prática educativa desses profissionais e os desafios e saberes que eles concebem como importantes para sua prática. Concluíram que os professores "reconhecem sua origem social, formação acadêmica, presença ou não de formação pedagógica para a docência, ou seja, sua própria história de vida como fator que favorece o desempenho na sala de aula". (Silva e Santos, 2016, p. 5362).

A produção de Pena (2010) buscou evidenciar os elementos para a compreensão do ser professor na EP, abordando as especificidades do trabalho docente, tomando como referência os estudos sobre saberes docentes e constituição da identidade. Pena (2010) concluiu que há a necessidade de realização de pesquisas que investiguem as percepções dos professores sobre a atuação na EP, pois acredita que elas possam indicar como se percebem enquanto professores de instituição dessa natureza.

A pesquisa de Lima, Baldino e Fernandes (2012) teve como foco a docência tecnológica, interrogando se os diversos discursos existentes sobre ela têm ressonância no cotidiano do fazer docente e se apontam para a construção de uma determinada identidade docente, ou seja, para um determinado habitus professoral. A pesquisa concluiu que há ausência de política global de formação de docentes para atuar no ensino superior e tecnológico, “[...], pois os cursos de graduação existentes não qualificam docentes para exercerem suas funções no ensino profissional tecnológico; os cursos de pedagogia não abordam questões voltadas ao trabalho e à educação profissional" (Lima, Baldino e Fernandes, 2012, p. 11).

O trabalho de Gariglio et al; Burnier; Oliveira; Silva; Valentim (2012) teve por objetivo a observação e análise dos saberes pedagógicos edificados pelos docentes da EPT no exercício 
cotidiano do ensino de conteúdos vinculados às áreas profissionais. Concluiu pela existência de quatros tipos de fontes que constituem os saberes docentes: os saberes laborais; os conhecimentos dos conteúdos da disciplina; os conhecimentos da história de vida e os conhecimentos pedagógicos incorporados na experiência profissional na sala de aula, formação em serviço ou cursos de licenciatura.

Paiva e Henrique (2015) abordaram a constituição profissional docente e os saberes necessários à prática docente e, como se tratou de pesquisa bibliográfica, tomaram como aporte os estudos de Tardif e Pimenta, abordando as tipologias dos saberes docentes.

O artigo de Silva e Henrique (2017) buscou compreender os saberes que os docentes da EP utilizam para fundamentar as práticas pedagógicas no exercício cotidiano, tendo em vista sua base de formação, principalmente os professores não licenciados. Como a pesquisa estava em andamento, o trabalho apresentou a revisão teórica acerca da formação do docente não licenciado para a EP e como se constroem os saberes docentes na conformação das práticas pedagógicas.

Brito e Cruz (2017) analisaram a formação, os conhecimentos necessários e o processo de construção da identidade do professor na e para a EP. Os dados da pesquisa indicam que a referência da formação de bacharelado ainda é predominante e os conhecimentos pedagógicos não ocupam papel importante na preparação dos professores para o exercício da profissão.

Quanto a base teórica dos estudos, na maioria dos resumos constatou-se a ausência desta informação. Analisando os autores neles citados, há a influência marcante de Tardif/Tardif; Lessard ${ }^{4}$, em nove trabalhos, e outros autores como Shulman, Schön, Nóvoa, Freire, Pimenta (três trabalhos); Lessard, Perrenoud, Imbernon (dois trabalhos) e Charlot, Zeichner, Contreras, Garcia, Grillo, Grosman, Gudmundsdóttir; Shulman, Seggal, Moita e Larrosa (um trabalho). Relacionado à formação de professores para a EP, são recorrentes as citações a Kuenzer, Machado, Ciavatta, Moura, dentre outros.

\subsubsection{Análise das políticas de formação de professores para a EP}

Esta categoria foi tema de doze produções que tiveram por escopo analisar as políticas de formação de professores para a EP, sendo que nove foram produzidos por meio de pesquisa bibliográfica e quatro são documentais, resultantes da análise de leis, decretos e pareceres referentes ao tema. Os trabalhos, em sua maioria, foram elaborados como revisão de literatura para teses e dissertações em andamento nos Programas de Pós-Graduação.

Oliveira (2010) teve por objetivo apontar características da formação de professores para a EP e constatou que a área sofre com a ausência de marcos regulatórios próprios e de políticas públicas de formação, e é efetivada por meio de programas emergenciais. Apontou a carência de

\footnotetext{
${ }^{4}$ Optou-se por omitir o ano das obras porque são diferenciados entre os autores analisados e sobrecarregam o texto, sem contribuir efetivamente para a identificação da fonte.
} 
estudos sobre o tema, que atribui a "[...] dada concepção sobre as relações entre experiência profissional e formação acadêmica, permeada por um não reconhecimento da docência na EP como um campo de conhecimento com identidade própria" (Oliveira, 2010, p.461).

Silva (2014) teve como propósito refletir sobre os desafios que se põem para a formação dos professores para a EP e analisa as políticas de formação desses professores. Aponta para a necessidade da criação de políticas educacionais de caráter nacional, contínuas e obrigatórias e de alcance pela totalidade dos profissionais que nela atuam.

O estudo de Barbosa e Passos (2014) objetivou cooperar para a construção de políticas públicas específicas para a formação de professores da EP, refletindo sobre a contribuição da educação a distância na formação desses docentes. Concluiu ser essa uma alternativa viável, desde que os cursos estejam embasados em propostas bem definidas, com objetivos claros e prática voltada às reais necessidades do aluno, do professor, da EP e do mercado a que se destina.

Barbosa (2016) analisou a formação de professores para a EP nos contextos da Argentina, Chile e Brasil diante das novas exigências do mundo do trabalho, procurando identificar as fragilidades e os desafios dessa modalidade de ensino. Barbosa (2016) apontou a necessidade da produção de conhecimento e urgente definição de políticas públicas para a formação dos docentes da EP na perspectiva de integração educação-trabalho, pois considera fundamental ao docente saber articular teoria, técnica e prática para que os desafios das sociedades modernas sejam realmente enfrentados e solucionados.

O trabalho de Costa (2012) teve por objetivo identificar e problematizar as políticas de formação de professores para a EP. Para tanto, analisou os desenhos curriculares dos cursos de licenciaturas dos institutos mineiros, identificando os pressupostos que conduzem as políticas de formação de professores para a EP. Concluiu que ainda são ofertados poucos cursos de formação de docentes para a EP na Rede Federal naquela região, o que é contraditório, já que "[...] apesar de existir um fosso na formação desses profissionais, a rede federal que é o lócus de formação do trabalhador, não prioriza a formação dos docentes para nela atuar" (Costa, 2012, p. 19).

Andrade e Souza (2015) apresentam um estudo documental e bibliográfico sobre formação de professores para a EP ancorado na normatização (leis e pareceres) e referenciais teóricos no contexto dos últimos trinta anos e concluíram que há morosidade na proposição de ações efetivas para a formação dos professores da EP.

Rodrigues e Souza (2015) traçaram o histórico das ações do poder público, no século XX, relativas à formação de docentes da EP e apontam que essa modalidade de ensino carece de políticas públicas que lhes dê maior estabilidade e corrija a pouca relevância que lhe foi dada durante séculos, muito embora não se possam esquecer os avanços das últimas décadas. Segundo os autores, formar professores para a EP não se faz apenas com decretos, ajustes na lei ou criação de cursos aligeirados, mas com políticas adotadas pelo poder público e assumida pelos profissionais envolvidos com essa modalidade de ensino.

Medeiros e Tavares (2015) mapearam os estudos sobre as políticas de formação de professores da EP e a iniciação à docência no PIBID entre os anos de 2010 a 2014, tendo como 
fonte o banco de dissertações e teses da CAPES. Identificaram que a produção científica nessa área está concentrada em programas de mestrado, especialmente no mestrado profissional.

O estudo de Meneses Filho e Costa (2017) teve por objetivo apreender e problematizar as políticas públicas para a formação de professores para a EP, sob o olhar da legislação brasileira entre 1917 e 2017 e constataram que a legislação é flexível quanto à formação desses professores, permitindo cursos emergenciais e especiais, o que os torna frágeis, sem, contudo, evidenciar a obrigatoriedade da licenciatura.

Costa e Coutinho (2017) analisaram as normativas e regulamentações oficiais para a formação de professores da EP com a finalidade de refletir e problematizar a Reforma do Ensino Médio, Lei no 13.415/2017, no que tange ao favorecimento do acesso de profissionais com notório saber. Concluíram que referida lei representa um retrocesso no campo de formação de professores para a EP.

O trabalho de Machado (2017) analisou as ideias e ações que permeavam a formação docente para o ensino técnico entre as décadas de 1940 e 1950, nos cursos de formação oferecidos pela Comissão Brasileiro Americana de Ensino Industrial (CBAI) e como as propostas para a formação docente foram expressas no Seminário Latino Interamericano de Formação Profissional (1952), observando em que aspectos se coadunavam com as propostas da CBAI, porém, expressos no contexto da América Latina.

Costa, Silva e Lemos (2017) analisaram a reconfiguração nacional da formação de professores para a EP, a partir das implicações da Reforma do Ensino Médio - Lei no 13.415/2017. Os autores defendem que a política implementada pela reforma, especialmente o notório saber, agiliza a desprofissionalização do professor, precariza ainda mais seu trabalho, ampliando o número de profissionais que atuarão na docência como uma sub ocupação.

A exemplo do afirmado em relação aos trabalhos anteriores, também nas pesquisas inseridas nesta categoria estão ausentes os referenciais teóricos. Quanto aos autores que as subsidiaram, os estudos partem da análise da legislação pertinente e/ou nas produções de pesquisadores da área da EP, especialmente Kuenzer, Machado, Ciavatta, Oliveira e Moura.

\subsubsection{Análise de programas ou cursos de formação de professores para a EP}

Constituíram essa categoria cinco trabalhos que se aproximam por analisar os resultados de experiências de formação de professores para a EP, efetivadas por meio de programas especiais ou cursos de especialização lato sensu.

Santos, Fighera e Juchem (2012) relataram experiência de formação de professores de um IFE por meio de um Programa Especial de Graduação de Formação de Professores para a Educação Profissional, oferecido por uma universidade pública. As narrativas dos participantes evidenciaram como um dos problemas do curso a forma como os docentes que nele atuam concebem a formação pedagógica para os professores, pois "[...] ainda é forte a concepção de formação pedagógica relacionada à ideia de transmissão de conhecimentos referentes a estratégias didático-pedagógicas que auxiliem a organizar e por em ação o trabalho em sala de aula" (Santos, 
Fighera e Juchem, 2012, p.7). O estudo conclui que é imperativo identificar as necessidades formativas inerentes à atividade do professor da educação profissional e tecnológica para que uma formação reflexiva e, principalmente significativa, se concretize.

O trabalho de Liberalesso (2010) abordou a formação pedagógica de docentes da Rede Federal de Educação Tecnológica a partir do Programa Especial de Formação Pedagógica para Docentes ofertado no IFFarroupilha-RS no ano de 2009 nos moldes instituídos pela Resolução CNE/CEB n 2/1997. Assim, traçou o histórico da implantação dos IFES, as normativas que respaldam a profissionalização da educação, a inserção dos profissionais liberais nas instituições escolares como docentes, as demandas de formação pedagógica destes sujeitos e as possibilidades da edificação de tempos/espaços de formação, que estejam sustentados na reflexão das práticas efetivadas. Liberalesso (2010) concluiu que os cursos de formação de professores estão pautados no modelo da racionalidade técnica e apontou os desafios e possibilidades dessa formação.

Wollinger, Allain e Gruber (2017) informam que o trabalho "apresenta uma proposta inovadora de formação docente para a EP" (p.1), baseada em uma epistemologia da EP, materializada no princípio da interdisciplinaridade ampla, e de uma didática própria para as atividades relativas à formação para o trabalho, a exemplo da didática profissional francesa. Após a abordagem de tais pressupostos, apresentam a proposta de um curso de Pós-Graduação para a docência na EP ofertado pelo Instituto Federal de Santa Catarina, destinado aos professores da área técnica, fundamentada na tecnologia como ciência da técnica. No entanto, não ficou claro, no relato, como aquela proposta dialoga com os pressupostos expressos no trabalho.

Vieira, Vieira e Pasqualli (2015) analisaram como egressos de um Programa Especial de Formação Pedagógica de Docentes para a Educação Profissional ofertado no Instituto Federal de Educação, Ciência e Tecnologia do Rio Grande do Sul caracterizaram seu processo de formação docente, avaliaram em que medida a formação para a docência provoca alterações nas suas concepções e identificaram os desafios que se deparam no processo de constituição docente. Os resultados da pesquisa indicaram que o referido programa contribuiu significativamente no processo de constituição da profissionalidade dos professores da EP, qualificando-os para a docência.

Nascimento Júnior e Leiro (2017) apresentaram uma proposta de pesquisa em andamento que tem por objetivo apontar indicadores que possam contribuir para a elaboração de uma proposta de itinerário formativo - curso de Pós-Graduação lato sensu, de caráter pedagógico - a ser ofertada pelo Instituto Federal de Educação, Ciência e Tecnologia da Bahia (IFBA), e destinado a professores não licenciados da EP, levando em consideração informações sobre suas trajetórias acadêmicas e suas necessidades pedagógicas.

Embora seja tarefa difícil classificar os autores citados nos trabalhos que compuseram essa categoria, grosso modo se pode apontar dois grupos: o primeiro é constituído pelos autores que pesquisam sobre EP no Brasil, como Kuenzer, Machado, Ciavatta, Oliveira, dentre outros, e o segundo grupo pesquisa o tema formação de professores, como Imbernon, Nóvoa, Garcia, Gómez, Isaia e Bolzan, Pimenta. 


\subsubsection{Formação e trabalho docente}

Oito trabalhos, cuja centralidade reside na análise da relação entre formação e trabalho docente na EP, constituíram essa última categoria.

O foco do trabalho de Araújo (2010) residiu nas estratégias formativas e no lócus indicado para a formação dos professores da EP, as especificidades da atividade docente e a existência de uma possível didática da EP.

Para essa mesma direção converge o trabalho de Kuenzer (2010) que versa sobre a formação de professores para a EP e aponta como lócus os cursos superiores de licenciatura, consideradas as suas especificidades, já que entende que esses docentes deverão ter a mesma base comum de formação pedagógica que os demais professores, além de uma "[...] especificidade que confere complexidade a sua formação: a necessidade de conhecimento sobre a área específica de trabalho a ser ensinada, que deve articular conhecimento científico e conhecimento tácito" (Kuenzer, 2010, p.503). Aponta ainda as dificuldades de articular esses conhecimentos na formação dos professores.

Cruz (2016) inventariou a produção acadêmica sobre trabalho e formação docente para a EP, defendidas no período de 2008 a 2014 e concluiu foi que a maioria dos estudos direcionou mais a formação na perspectiva do sujeito, e o par dialético trabalho-formação foi pouco explorado, o que pode reproduzir, muitas vezes, lógica pragmática e de responsabilização do professor. Contudo, o estudo identificou conteúdos formativos que podem abrir perspectivas coletivas de construção da docência na EP, como o conhecimento e a pesquisa sobre a educação; a constituição de unidade entre os conhecimentos didáticos dos conteúdos e os conhecimentos das profissões de origem; unidade teoria-prática; formação política e social; relação educação e trabalho e sujeitos da educação profissional.

O artigo de Pasqualli, Vieira e Vieira (2015) catalogou as produções acadêmicas do período de 2010 a 2015 sobre formação de professores para a EP a distância na Rede Federal de Educação Brasileira, apresentados em Programas de Pós-Graduação Stricto Sensu e em eventos científicos e constatou a quase inexistência de pesquisas relacionadas à problemática anunciada. $O$ estudo apontou que, timidamente, surgem trabalhos que iniciam discussões sobre o tema e em maior proporção para a EAD.

Henrique e Cavalcante (2015) relataram experiência de formação por meio de pesquisa realizada no Instituto Federal de Educação, Ciência e Tecnologia do Rio Grande do Norte na qual investigaram quem são os docentes da EP, como percebem a sua formação, se estabelecem práticas integradoras ou interdisciplinares, articulando os diferentes núcleos que compõem os cursos técnicos, se compreendem a função emancipatória e omnilateral da educação básica, técnica e tecnológica, entre outros aspectos. O trabalho apresentou o relato das atividades desenvolvidas na pesquisa, porém os dados coletados não foram nele incluídos.

Souza, Silva e Silva (2005) pesquisaram as percepções dos docentes da EP acerca da formação integral e integrada no Ensino Médio Integrado à Educação Profissional e Tecnológica e apontaram que tais concepções, apesar de fazer parte dos documentos institucionais, ainda não 
foram epistemologicamente apropriadas pelos docentes e, portanto, não se materializam em seu fazer cotidiano.

Silva e Souza (2015) investigaram professores bacharéis que atuam nos cursos de Engenharia Elétrica do Instituto Federal de Educação, Ciência e Tecnologia da Paraíba procurando evidenciar como compreendem o currículo daqueles cursos. Constataram que há uma compreensão limitada sobre o tema, pois as discussões se reduzem a aspectos como carga horária, ementas das disciplinas e estrutura física, secundarizando o aprofundamento de outras nuances do tema.

Refletir acerca das possibilidades de formação docente para o uso das TIC na EP na perspectiva da formação humana integral foi o objetivo do trabalho de Mororó e Nascimento (2017) que abordam as tecnologias e seu impacto no mundo do trabalho e na educação e os caminhos possíveis para formação docente para o uso das TIC de forma dialógica com a perspectiva da formação humana integral. Consideram que a formação docente na perspectiva defendida é fundamental, dado que implica em mudanças nas práticas que contribuem na formação discente.

Quanto ao aporte teórico dos trabalhos, Araújo (2010), Kuenzer (2010) e Cruz (2016) citam o materialismo histórico, enquanto nos demais não há identificação. Em relação aos autores que embasaram os trabalhos, nesta categoria também é possível apontar a existência de dois grupos: o dos pesquisadores da EP, como Machado, Moura, Frigotto; Ciavatta; Ramos, Oliveira, Araújo, dentre outros, e o segundo grupo onde estão incluídos autores que tratam da constituição e saberes docentes, como Tardif, Pimenta, Freire e Morin.

\subsection{Metodologia dos estudos}

Foram analisados nos trabalhos o percurso metodológico de produção dos dados, identificando a classificação da pesquisa quanto ao tipo, abordagem do problema, técnicas e instrumentos de produção dos dados, lócus e sujeitos pesquisados.

Quanto ao tipo de pesquisa, dos trinta e nove trabalhos analisados, treze autores os identificaram como qualitativa, um como quanti-qualitativa e em vinte e cinco trabalhos não há referência sobre a classificação. Chama a atenção que a identificação está presente nas pesquisas de campo e ausente na maioria das pesquisas bibliográficas ou documentais. Em três trabalhos há referência a abordagem autobiográfica, duas foram classificadas como fenomenológicas, uma como sociocultural e uma como crítico-reflexiva.

No que se refere aos procedimentos adotados, constatou-se que catorze estudos se caracterizam como de campo, treze são bibliográficas e cinco documentais. Os trabalhos de caráter bibliográfico e documental geralmente fazem parte de teses e dissertações em andamento, enquanto as pesquisas de campo relatam pesquisas concluídas.

Nas catorze pesquisas de campo, os instrumentos de produção de dados utilizados foram a entrevista (nove pesquisas); história de vida (duas) questionário (duas) e observação (uma). Por tratar-se de estudos referentes à formação de professores, eles são os principais sujeitos 
investigados nas catorze pesquisas de campo, sendo que em apenas uma foram incluídos os gestores da instituição pesquisada e uma foi realizada com alunos de cursos técnicos. Prevalecem pesquisas com baixo número de sujeitos, principalmente quando se faz uso da entrevista e da observação, caso em que foram investigados até cinco professores (três ocorrências), de seis a dez professores (cinco ocorrências) e mais de dez sujeitos (três ocorrências), sendo que dois não informam o número de professores pesquisados. Nas duas pesquisas em que foram aplicados questionários, o número foi de 198 alunos e de 99 docentes.

Em relação ao lócus dos trabalhos, as catorze pesquisas de campo tomaram como espaço de estudo os Institutos Federais de Educação, Ciência e Tecnologia e apenas um incluiu também três instituições pertencentes a outras redes de ensino.

\section{CONCLUSÕES}

Concluído o inventário das produções acadêmicas o primeiro aspecto em destaque é que estudos realizados sobre formação de professores para EP no período anterior a 2009 indicavam consenso de que o tema era objeto de poucas investigações. Analisando as produções a partir de 2010 constatou-se que houve significativo crescimento e o tema repercutiu nacionalmente nos eventos da área. Uma hipótese possível para explicar esse aumento pode ser a criação e expansão do IFEs em 2008 e a consequente ampliação do número de docentes que passou a atuar nessa modalidade de ensino. Essa visibilidade chamou a atenção para as problemáticas envolvidas na implantação de cursos pelos IFES que se tornou temática de estudos acadêmicos.

No tocante aos conteúdos abordados nos trabalhos, boa parte centraliza-se na constituição da professoralidade, enfocando os saberes docentes e a constituição da identidade de professor. Mas ainda se encontram presentes estudos que realizam retrospectivas históricas da EP e análises da legislação pertinente às políticas de formação de professores e, em menor número, há estudos que enfocam a relação formação e trabalho docente na EP. Registre-se ainda a pouca ocorrência de relatos de experiências de cursos de formação para docentes, já que nenhum abordou a oferta de cursos de licenciatura, um enfocou curso de Pós-Graduação (especialização) na área, outro foi elaborado para apontar subsídios para elaboração do projeto de curso de especialização e três foram realizados em Programas Especiais de Formação Pedagógica de Docentes para o Ensino Fundamental e Médio (Resolução CNE/CEB n. 02/97).

Quanto aos procedimentos metodológicos, a maioria dos estudos não identificou o tipo, abordagem ou técnica da pesquisa. Preponderam as pesquisas bibliográficas ou documentais e nas pesquisas de campo o instrumento mais utilizado para a produção de dados foi a entrevista e não há informações sobre os procedimentos utilizados para análise de dados. Outro aspecto que emergiu da análise dos trabalhos é a constatação que os IFES são o lócus das pesquisas sobre o tema.

Por fim, é importante mencionar a importância de dois eventos para a divulgação de pesquisas sobre formação de professores para a EP: o SENEPT, do CEFET - MG, e o Colóquio Nacional A Produção do Conhecimento em Educação Profissional, do IFRN. Referidos eventos se 
constituem em espaços para divulgação das pesquisas em andamento nos programas de PósGraduação das instituições promotoras, mas também contam com a presença de pesquisadores de outras instituições localizadas em várias regiões do país.

\section{REFERÊNCIAS}

Baptaglin, L. A. (2013). A educação profissional e tecnológica e a aprendizagem da docência: o que está sendo pesquisado nas produções acadêmico-científicas? XI Congresso Nacional de Educação. Disponível em: <educere.bruc.com.br/ANAIS2013/pdf/7518_4366.pdf>. Acesso em: 19 jun.2014.

Bardin, L. (2002) Análise de conteúdo. Lisboa: Edições 70.

Bolzan, D. P. V., Isaia, S. M. de A. (2010). Pedagogia Universitária e aprendizagem docente: relações e novos sentidos da professoralidade. Revista Diálogo Educacional, Curitiba, 10, pp. 13-26, jan./abr.

Brasil. Ministério da Educação. Rede Federal de Educação Profissional, Científica e Tecnológica. (2016). Expansão da Rede Federal de Educação Profissional, Científica e Tecnológica. Disponível em: http://redefederal.mec.gov.br/expansao-da-rede-federal. Acesso em: 31 nov. 2017.

Gariglio, J. A., Burnier, S. (2012). Saberes da docência na educação profissional e tecnológica: um estudo sobre o olhar dos professores. Educação em Revista: Belo Horizonte. 28(01), pp.211236. mar.

Gatti, B. A., Barretto, E. S. de S (2009). Professores do Brasil: impasses e desafios. Brasília: Unesco.

Gatti, B. A., Barretto, E. S. De S., André, M. E. D. A (2011). Políticas docentes no Brasil: um estado da arte. Brasília: Unesco.

Haddad, S. (2002). Juventude e escolarização: uma análise da produção de conhecimentos. Brasília/DF: MEC/Inep/Comped.

Machado, L. R. S. (2008). Diferenciais inovadores na formação de professores para a educação profissional. Revista Brasileira da Educação Profissional e Tecnológica, 1(1), jun. 2008. Brasília: MEC/SETEC, 2008.

Pena, G. A. C. (2011). Formação docente e aprendizagem da docência: um olhar sobre a educação profissional. Educação em Perspectiva, Viçosa, 2(1), pp. 98-118, jan./jun.

Veiga, I. P. A., Quixadá, C. Q. (2010). Docentes para a Educação Superior: processos formativos. Campinas, São Paulo: Papirus. 